\title{
EFEITO DE DIFERENTES NÍVEIS DE PROTEÍNA E DE FIBRA BRUTA NA ALIMENTAÇÃO DE JUVENIS DE MATRINXÃ, Brycon cephalus ${ }^{1}$.
}

\section{Manoel PEREIRA-FILHO ${ }^{2}$, Newton CASTAGNOLLP, Atílio STORTI-FILHO ${ }^{2}$ Maria I, de OLIVEIRA-PEREIRA ${ }^{2}$}

\begin{abstract}
RESUMO - São apresentados os resultados de um experimento realizado com matrinxãs, Brycon cephalus, alimentados com nove dietas contendo três níveis de proteína $(19,25$ e $31 \%)$ combinados com três níveis de fibra (cerca de 2, 10 e 20\%). O peso final foi mais elevado para os peixes que receberam ração com maiores níveis de proteína bruta, mas não foi afetado pela elevação dos níveis de fibra bruta. Os níveis mais elevados de proteína na ração aumentaram o conteúdo de proteína da carcaça, e diminuiram o conteúdo de gordura e cinza, enquanto os peixes alimentados com as rações com os níveis mais elevados de fibra tinham mais proteína e cinza corporal e menores níveis de gordura. Os resultados sugerem que ingredientes com níveis elevados de fibra são bem utilizados pelo matrinxã, aumentando desta maneira a variedade de subprodutos agrícolas, normalmente ricos em fibra bruta, que podem ser usados na formulação de dietas práticas para esta espécie.
\end{abstract}

Palavras-chave: Matrinxã, Brycon cephalus, Proteína bruta, Fibra bruta.

Protein and Crude Fiber Levels in the Diet of Juvenile Matrinxã, Brycon cephalus, an Amazonian Fish.

ABSTRACT - The results of an experiment with matrinchã, Brycon cephalus, fed 9 diets, combined in 3 levels of protein (19,25 e 31\%) and 3 levels of fiber (ca. 2, 10 and 20\%), are shown. The final weight was positivelly influenced when fish fed higher levels of protein, but was not influenced by fiber levels. The higher levels of protein in the diet, increased protein content of carcass, and decreased the content of fat and ash, while fish fed the highest fiber levels assimilated more protein, had a higher percentage of ash and a lower fat content in the body composition. The results indicated that ingredients with high levels of fiber are well assimilated by matrinchã, increasing this way the range of agricultural by-products, normally rich in fiber, that could be used to formulate practical diets for this specie.

Key words: Matrinxã, Brycon cephalus, Crude protein, Crude fiber.

\section{INTRODUÇÃO}

Várias espécies de peixes da região amazônica são onívoras, tendendo a herbívoras, como o tambaqui (Colossoma macropomum) e a pirapitinga (Piaractus brachypomus), enquanto outras são essencialmente herbívoras, como vários representantes da família Anostomidae e membros do gênero Brycon (MENEZES, 1969;
GOULDING, 1980; FLAMM, 1983; SANTOS, 1991; FERREIRA, 1992). Na dieta de todas elas a fibra está presente em variáveis proporções.

O efeito da fibra na ração dos peixes ainda é um assunto em discussão, tendo sido estudado por FURUKAWA \& OGASAWARA (1952); BUHLER \& HALVER (1961); LEARY \& LOVELL (1975); HILTON et al. (1983); UFODIKE \& MATTY

\footnotetext{
Suporte financeiro da $\mathrm{FBB}$ e $\mathrm{CNPq}$

2 INPA/CPAQ, CP 478, 69.083-000, Manaus/AM, Brasil

3 UNESP-Jaboticabal, 14.870-000, Jaboticabal/SP, Brasi]
} 
(1983); ANDERSON et al. (1984); DAVIES (1985); LÉSEL et al. (1986); SHIAU et al. (1988); PEREIRA-FILHO (1989) e DIOUNDICK \& STOM (1990).

A partir da década de 70 , vários pesquisadores começaram a trabalhar com algumas espécies de peixes amazônicos, como o tambaquí (Colossoma macropomum) e o matrinxã (Brycon cephalus), passando a haver a necessidade de se conhecer em maior profundidade as exigências nutritivas destas espécies, inclusive o efeito de níveis diferentes de proteína e fibra bruta em suas dietas.

O objetivo deste trabalho foi avaliar o efeito de níveis de proteína e fibra bruta em dietas, através do crescimento e da composição corporal de juvenis de matrinxã (Brycon cephalus), e desta forma obter informações que permitam o uso de resíduos da agricultura na criação desta espécie.

\section{MATERIAIS E MÉTODOS}

Foi feita a análise bromatológica dos ingredientes e em seguida foram formuladas nove rações (Tab. 1), contendo três níveis de proteína $(19,25$ e $31 \%$ ) combinados com três níveis de fibra bruta (ca. 2, 10 e $20 \%$ ).

$\mathrm{O}$ experimento foi conduzido no INPA, Manaus/AM, Brasil, utilizandose 27 tanques de cimento-amianto com capacidade de $1 \mathrm{~m}^{3}$ cada, cobertos com uma tela, com fornecimento constante de água e aeração suplementar.

Para a análise estatística dos resultados usou-se um esquema fatorial $3 \times 3$, com três repetições por tratamento, em um delineamento inteiramente casualisado. A média de cada tanque representou uma unidade experimental.

Os animais utilizados neste experimento, juvenis de matrinxã (Brycon cephalus) com peso médio de $125 \mathrm{~g}$, foram coletados no rio Solimões, nas proximidades de Manaus, e mantidos em laboratório até o início do experimento. Estocouse cinco exemplares por tanque e em seguida fez-se sorteio para distribuição dos tratamentos nos diferentes tanques experimentais. Foram realizadas quatro amostragens, uma após um período de adaptação de dez dias e as outras a intervalo de 28 dias, com um período de observações de 84 dias. Em cada amostragem foram pesados todos os peixes de cada tanque.

Os peixes foram alimentados à vontade duas vezes ao dia, com as rações sendo fornecidas na forma de grânulos úmidos (50\% de umidade), pela manhã e à tarde.

A temperatura da água dos tanques foi medida duas vezes ao dia. Semanalmente foram determinad's os teores de oxigênio dissolvido,- pelo método de Winkler modificado (BOYD, 1990), a condutividade elétrica e o $\mathrm{pH}$ da água dos tanques.

Após o período de crescimento, os peixes de todos os nove tratamentos foram triturados por lote, homogeneizados e feita uma secagem parcial a $55^{\circ} \mathrm{C}$ durante 24 horas em estufa. A seguir, o material foi moído e determinados os teores de umidade por dessecação até peso constante a $105^{\circ} \mathrm{C}$. Os teores de proteína foram 
Tabela 1. Composição das dietas. P1, P2, e P3 são os níveis de proteína $(19,25$ e $31 \%$ respectivamente). F1, F2 e F2 são os níveis de fibra bruta (ca. 2, 10 e 20\%, respectivamente)

FORMULACÃO DE CADA DIETA (\%)

\begin{tabular}{lcccccc}
\hline Dietas & Soja & Far.peixe & Amido & Milho & Celulose & Premix \\
P1F1 & 21,8 & 12,5 & 53,7 & 10,0 & 0,0 & 2,0 \\
P1F2 & 21,8 & 12,5 & 44,7 & 10,0 & 9,0 & 2,0 \\
P1F3 & 21,8 & 12,5 & 34,7 & 10,0 & 19,0 & 2,0 \\
P2F1 & 30,0 & 17,3 & 40,7 & 10,0 & 0,0 & 2,0 \\
P2F2 & 30,0 & 17,3 & 31,7 & 10,0 & 9,0 & 2,0 \\
P2F3 & 30,0 & 17,3 & 21,7 & 10,0 & 19,0 & 2,0 \\
P3F1 & 38,2 & 22,0 & 27,8 & 10,0 & 0,0 & 2,0 \\
P3F2 & 38,2 & 22,0 & 18,8 & 10,0 & 9,0 & 2,0 \\
P3F3 & 38,2 & 22,0 & 8,8 & 10,0 & 19,0 & 2,0 \\
\hline
\end{tabular}

Tabela 2. Composição proximal de cada dieta (\%).

\begin{tabular}{lcccccc}
\hline Dietas & Umidade & Proteina & Gordura & Cinza & Fibra & ENN $^{2}$ \\
\hline P1F1 & 7,8 & 19,2 & 1,0 & 6,3 & 1,5 & 64,2 \\
P1F2 & 7,6 & 19,4 & 1,0 & 6,8 & 10,2 & 54,5 \\
P1F3 & 7,4 & 18,9 & 1,0 & 7,2 & 19,6 & 45,9 \\
P2F1 & 7,9 & 25,8 & 1,2 & 9,0 & 2,4 & 53,7 \\
P2F2 & 8,1 & 25,7 & 1,4 & 8,7 & 10,4 & 45,7 \\
P2F3 & 7,5 & 25,4 & 1,3 & 10,4 & 20,4 & 35,0 \\
P3F1 & 7,4 & 30,7 & 1,7 & 9,6 & 3,9 & 46,7 \\
P3F2 & 7,1 & 30,4 & 1,4 & 9,0 & 10,7 & 41,4 \\
P3F3 & 7,2 & 31,8 & 1,1 & 9,8 & 20.2 & 29,9 \\
\hline
\end{tabular}

'Valor obtido após a secagem para análise; ${ }^{2} \mathrm{E} \mathrm{N} \mathrm{N}=$ Extrativos não nitrogenados

determinados pelo método de microKjeldahl, usando-se como fator de multiplicação 6,25 ; a gordura, em extrator de Soxleth, usando-se éter de petróleo como solvente; a cinza, por queima em mufla a $550^{\circ} \mathrm{C}$ durante três horas, segundo AOAC (1980).

Ao final do período experimental, foram feitas as análises estatísticas dos resultados obtidos, de acordo com BANZATTO \& KRONKA (1989), para avaliar o efeito das diferentes dietas sobre o peso médio final e a composição corporal dos peixes.

\section{RESULTADOS}

$\mathrm{Na}$ análise estatística dos dados de peso final dos peixes, observou-se que o fator fibra não influenciou significativamente o peso final dos peixes (médias de 151,2, 161,0 e 158,2g, para os níveis de fibra ca. $2 \%, 10 \%$ e $20 \%$, respectivamente), mas o efeito da proteína foi significativo $(\mathrm{P}<0,05)$. Através do teste de Tukey observou-se que os níveis de proteína de 25 e $31 \%$, que não diferiram entre si, proporcionaram peso médio 
final superior ao proporcionado pelo nível de $19 \%(132,9,70,9 \mathrm{e}$ $166,6 \mathrm{~g}$, respectivamente)(Tab. 3 ).

A análise estatística dos dados de proteína corporal mostra que a elevação dos níveis deste nutriente nas dietas resultou em uma elevação no seu conteúdo. No entanto, os níveis de 25 e $31 \%$ de proteína não diferiram significativamente entre si e foram superiores aos valores encontrados para os animais que receberam o nível de $19 \%$ de proteína.Com relação ao efeito da fibra, observou-se que a elevação dos seus teores resultou em elevações significativas nos valores de proteína corporal.

Considerando os efeitos isolados dos fatores proteína e fibra das rações sobre o teor de gordura corporal, observou-se que apenas a fibra influenciou este parâmetro, provocando sua diminuição.
Os valores encontrados para cinza corporal mostram que os dois teores mais elevados de proteína das dietas resultaram em valores de cinza corporal que não diferiram entre sí, porém foram inferiores aos encontrados para o nível de $19 \%$ de proteína. A elevação dos níveis de fibra dietária resultaram em elevações significativas nos níveis de cinza corporal.

Neste trabalho não foram observadas interações significativas entre os efeitos dos fatores proteína e fibra sobre os parâmetros estudados.

\section{DISCUSSÃO}

Os elevados preços das fontes protéicas de origem animal tornam necessário o uso de proteína vegetal na formulação de dietas. A composição de tais alimentos leva a um aumento no nível da fibra dietária, a qual inclui entre

Tabela 3. Teste de Tukey para o efeito dos níveis de protefna e fibra das rações sobre os fatores estudados. Médias na mesma coluna, com as mesmas letras não diferem entre sí $(P>0,05)$.

\begin{tabular}{lcrrr}
\hline PARÂMETRO ESTUDADO & \multicolumn{2}{c}{ EFEITO DA PROTEINA } & \multicolumn{2}{c}{ EFEITO DA FIBRA } \\
\hline & $25 \%$ & $170,9 \mathrm{a}$ & $10 \%$ & $161,0 \mathrm{a}$ \\
Peso médio final (g) & $31 \%$ & $166,6 \mathrm{a}$ & $20 \%$ & $158,2 \mathrm{a}$ \\
& $19 \%$ & $132,9 \mathrm{~b}$ & $\mathrm{ca} .2 \%$ & $151,2 \mathrm{a}$ \\
& & & & \\
& $25 \%$ & $36,0 \mathrm{a}$ & $\mathrm{ca} .2 \%$ & $36,3 \mathrm{a}$ \\
Matéria seca (\%MS) & $31 \%$ & $36,0 \mathrm{a}$ & $10 \%$ & $35,7 \mathrm{a}$ \\
& $19 \%$ & $35,6 \mathrm{a}$ & $20 \%$ & $34,9 \mathrm{a}$ \\
& & & & \\
& $31 \%$ & $49,6 \mathrm{a}$ & $20 \%$ & $50,7 \mathrm{a}$ \\
Proteína (\%MS) & $25 \%$ & $48,3 \mathrm{a}$ & $10 \%$ & $48,2 \mathrm{~b}$ \\
& $19 \%$ & $46,9 \mathrm{~b}$ & $\mathrm{ca} .2 \%$ & $46,0 \mathrm{c}$ \\
& $19 \%$ & $42,7 \mathrm{a}$ & $\mathrm{ca} .2 \%$ & $43,1 \mathrm{a}$ \\
Extrato etéreo (\%MS) & $25 \%$ & $40,9 \mathrm{a}$ & $10 \%$ & $42,4 \mathrm{a}$ \\
& $31 \%$ & $40,3 \mathrm{a}$ & $20 \%$ & $38,3 \mathrm{~b}$ \\
& $19 \%$ & $10,1 \mathrm{a}$ & $20 \%$ & $9,9 \mathrm{a}$ \\
Cinza (\%MS) & $31 \%$ & $9,5 \mathrm{~b}$ & $10 \%$ & $9,6 \mathrm{ab}$ \\
& $25 \%$ & $9,1 \mathrm{~b}$ & ca. 2\% & $9,2 \mathrm{~b}$ \\
\hline
\end{tabular}


seus constituintes alguns materiais vegetais de difícil digestão tais como a celulose, lignina e outros carboidratos complexos. Ainda não foi completamente elucidado o papel da fibra na nutrição dos peixes.

BURHLER \& HALVER (1961) observaram declínio no crescimento de salmões criados com dietas com níveis crescentes de celulose. LEARY \& LOVELL (1975) observaram que o catfish, quando criado com dieta contendo $8 \%$ ou mais de celulose, tem seu crescimento reduzido. MORITA et al. (1982) incluiram carboxymethylcellulose em dietas de "red sea bream" (Pagrus major), aos níveis de 0, 3, 6, 9 e $12 \%$, melhorando seu crescimento e conversão alimentar. KONO et al. (1987) observaram aumento de crescimento em "red sea bream" e "yellowtail" (Seriola quinqueradiata) alimentados com dietas suplementadas com $10 \%$ de celulose, enquanto a dieta controle ( $1 \%$ de celulose) diminuiu a taxa de crescimento. DIOUNDICK \& STOM (1990) alimentaram tilápias com rações contendo $0 ; 2,5 ; 5,0 ; 7,5$ e $10,0 \%$ de celulose. Segundo esses autores, o melhor rendimento foi entre 2,5 e 5,0\%, e os piores foram 0 e $10,0 \%$.

Ao contrário do que se tem observado com a maioria dos peixes estudados, não foi observado efeito negativo sobre o peso final do matrinxã (Brycon cephalus), que possa ser atribuido aos níveis de fibra presentes nas rações, provalmente porque na natureza, a fibra está presente em importantes ítens da dieta desta espécie. MENEZES (1969) e GOULDING (1980) relataram que o gênero Brycon é herbivoro, enquanto WERDER \&
SAINT PAUL (1978), após teste de crescimento, e CYRINO et al. (1986), após um teste de digestibilidade, concluiram que o matrinxã utiliza igualmente bem tanto proteína de origem animal quanto de origem vegetal. Como o matrinxã, ALLIOT et al. (1979) observaram que Dicentrarchus labrax também cresce igualmente bem com proteínas de origem vegetal e animal. REIMER (1982) observou que as atividades amilase, tripsina e lipase de Brycon cf. melanopterus podem ser aumentadas respectivamente com uma dieta rica em carboidrato, proteína ou gordura enquanto a pepsina não mostrou mudanças em atividade, demonstrando que Brycon, como outros grupos de peixes, são capazes de adaptar seu sistema digestivo à oferta de alimentos.

Com relação aos níveis de proteína da dieta, observamos que, embora os animais que receberam as rações que continham os níveis mais elevados (25 e $31 \%$ ) não apresentassem pesos diferentes entre si, estes eram superiores $(\mathrm{P}<0,05)$ ao peso apresentado pelos animais que receberam ração com $19 \%$ de proteína.

São variáveis as informações encontradas na literatura sobre a influência da composição das rações sobre a composição corporal dos peixes. Neste trabalho observamos que os teores de proteína e fibra contidos nas rações influíram na composição da carcaça dos peixes. A elevação dos teores de proteína nas dietas provocaram elevação nos níveis de proteína corporal, não afetaram significativamente os teores de lipídio e diminuíram os teores de cinza, enquanto os maiores níveis de fibra também elevaram os teores de proteína corporal, diminuiram 
SANTOS, G.M. 1991. Pesca e ecologia dos peixes de Rondônia. Tese de Doutorado. Convênio INPA/FUA, Manaus/AM. 213 pp.

SHIAU, S.; YU, H.; HWA, S.; YANG, S.; HSU, S. 1988. The influence of carboxymethylcellulose on growth, digestion, gastric emptying time and body composition of tilapia. Aquaculture, 70: 345-354.
UFODIKE, E.B.C.; MATTY, A.J. 1983. Growth responses and nutrient digestibility in mirror carp (Cyprinus carpio) fed different levels of cassava and rice. Aquaculture, 31: 41-50. WERDER, U.; SAINT-PAUL, U. 1978. Feeding trials with herbivorous and omnivorous Amazonian fish. Aquaculture, 15: $175-177$. 